University of Nebraska - Lincoln

DigitalCommons@University of Nebraska - Lincoln

USDA National Wildlife Research Center - Staff Publications
U.S. Department of Agriculture: Animal and Plant Health Inspection Service

1995

\title{
Feeding Responses to Predator-Based Repellents in the Mountain Beaver (Aplodontia rufa)
}

\author{
Gisela Epple \\ Monell Chemical Senses Center, Philadelphia, Pennsylvania \\ J. Russell Mason \\ U.S. Department of Agriculture, Animal and Plant Health Inspection Service, Animal Damage Control
}

Evgueny Aronov

Monell Chemical Senses Center, Philadelphia, Pennsylvania

Dale L. Nolte

USDA-APHIS-Wildlife Services, Dale.L.Nolte@aphis.usda.gov

Richard Hartz

Department of Chemistry, University of Pennsylvania

See next page for additional authors

Follow this and additional works at: https://digitalcommons.unl.edu/icwdm_usdanwrc

Part of the Environmental Sciences Commons

Epple, Gisela; Mason, J. Russell; Aronov, Evgueny; Nolte, Dale L.; Hartz, Richard; Kaloostian, Ron; Campbell, Dan; and Smith, Amos III, "Feeding Responses to Predator-Based Repellents in the Mountain Beaver (Aplodontia rufa)" (1995). USDA National Wildlife Research Center - Staff Publications. 823. https://digitalcommons.unl.edu/icwdm_usdanwrc/823

This Article is brought to you for free and open access by the U.S. Department of Agriculture: Animal and Plant Health Inspection Service at DigitalCommons@University of Nebraska - Lincoln. It has been accepted for inclusion in USDA National Wildlife Research Center - Staff Publications by an authorized administrator of DigitalCommons@University of Nebraska - Lincoln. 


\section{Authors}

Gisela Epple, J. Russell Mason, Evgueny Aronov, Dale L. Nolte, Richard Hartz, Ron Kaloostian, Dan Campbell, and Amos Smith III 


\title{
FEEDING RESPONSES TO PREDATOR-BASED REPELLENTS IN THE MOUNTAIN BEAVER $(A P L O D O N T I A \text { RUFA })^{1}$
}

\author{
GiSElA EPPLE \\ Monell Chemical Senses Center, 3500 Market Street, Philadelphia, Pennsylvania 19104 USA
}

J. Russell MASON

U.S. Department of Agriculture, Animal and Plant Health Inspection Service, Animal Damage Control, Denver Wildlife Research Center, \% Monell Chemical Senses Center, 3500 Market Street, Philadelphia, Pennsylvania 19104 USA

EVGUENY ARONOV

Monell Chemical Senses Center, 3500 Market Street, Philadelphia, Pennsylvania 19104 USA

DALE L. NolTE

U.S. Department of Agriculture, Animal and Plant Health Inspection Service, Animal Damage Control, Denver Wildlife Research Center, Olympia Field Station, 3625 93rd Avenue, SW, Olympia, Washington 98502 USA

RichaRd A. HARTZ

Department of Chemistry, University of Pennsylvania, Philadelphia, Pennsylvania 19104 USA

Ron KaLOOSTIAN

Monell Chemical Senses Center, 3500 Market Street, Philadelphia, Pennsylvania 19104 USA

DAN CAMPBELL

U.S. Department of Agriculture, Animal and Plant Health Inspection Service, Animal Damage Control, Denver Wildlife Research Center, Olympia Field Station, 3625 93rd Avenue, SW, Olympia, Washington 98502 USA

Amos B. Smith, III

Department of Chemistry, University of Pennsylvania, Philadelphia, Pennsylvania 19104 USA

Abstract. Predator odors have potential as feeding repellents for mammalian herbivores, including Aplodontia rufa, the mountain beaver. However, the repellency of major chemical constituents of natural predator scents for this species has not been evaluated. In this study, the effects of several synthetic sulfur compounds from predator scents on feeding by mountain beavers were assessed and compared to the effects of coyote (Canis latrans) urine. Retrieval of food by mountain beavers from bowls scented with either coyote urine, diluted with water to different concentrations, synthetic components of predator scents, or control odorants was studied. The following synthetic compounds were tested: $\Delta^{3}$-Isopentenyl methyl sulfide (IMS), a compound present in urine from several canid species; 2,2 dimethylthietane (DMT), a major constituent in anal gland secretion from the mink (Mustela vison); a 1:1 mixture of 2-propylthietane (PT) and 3-propyl-1,2-dithiolane (PDT), compounds occurring in anal gland secretions from the stoat (Mustela erminea) and the ferret (Mustela putorius). Habituation to PT plus PDT was studied by measuring consumption of dry pellets during continuous exposure to these compounds for $5 \mathrm{~d}$. In two-choice feeding trials mountain beavers retrieved significantly more food from bowls scented with water than from bowls scented with coyote urine. Dilution of urine had no statistically significant effect on food retrieval, but repellency tended to decrease with decreasing concentration. Mountain beavers retrieved less food scented with a 1:1 mixture of PT and PDT, compared to controls. However, they rapidly habituated to this mixture. None of the other compounds caused an avoidance response. These results show that complex natural predator scents are more effective feeding repellents than some of their major volatile components alone.

Key words: Aplodontia rufa; feeding repellents; mountain beaver; predator odors.

\section{INTRODUCTION}

Damage by mountain beaver severely limits regeneration of conifer forests in the Pacific Northwest. This primitive, herbivorous rodent causes millions of dollars

\footnotetext{
${ }^{1}$ Manuscript received 17 March 1994; revised 19 September 1994; accepted 10 November 1994.
}

of losses each year by harvesting plant material for food and storage in underground burrows (Feldhamer and Rochelle, 1982, Campbell, 1994). Currently, trapping, poisoning, and mechanical barriers are the most frequently used control methods. Habitat manipulation and destruction of burrow systems are also practiced. Each of these methods is costly and with the exception 
of poisoning, difficult to implement on a large scale (Campbell 1994). There is a critical need to develop alternative approaches. Repellents offer unique opportunities for safe and nonlethal reduction of damage inflicted by wildlife.

Predator odors have potential as repellents for herbivorous mammals. Many mammalian predators communicate with conspecifics by scent marking with urine, feces, and the secretions of specialized scent glands (Macdonald 1985). For the predator these chemical signals have the disadvantage that they reveal its presence to prey. Predator scents provide cues for predation risk assessment by prey, and monitoring of such scents in the environment may be an important component of the predator avoidance strategy of many mammals.

Foraging is an energetically essential activity that often exposes animals to predation. It is therefore not surprising that foraging decisions are frequently influenced by predation risk (Lima and Dill 1990). A number of studies, recently reviewed by Mason et al. (1994), show that the presence of predator scents near a food source has a strong influence on foraging behavior in many herbivores. Such scents cause area avoidance or a reduction in feeding from sources associated with them. Predator scents, or synthetic constituents of such scents, may be particularly effective repellents because responses to these stimuli are generally considered to be innate and resistant to habituation (key references: Müller-Schwarze 1972, Gorman 1984, Sullivan and Crump 1984, Sullivan et al. 1985a, Sullivan et al. 1988a, Swihart 1991, Arnould and Signoret 1993, Epple et al. 1993).

The composition of volatile constituents in excreta and scent gland secretions from mammalian carnivores is highly complex. Compounds from different groups, among them aldehydes, ketones, sulfur compounds, amines, and fatty acids, are present (Albone 1984). These represent a rich reservoir of potential repellents. However, only a relatively small number of constituents of natural predator scents has been synthesized and their repellency evaluated in laboratory and field studies (Vernet-Maury 1980, Sullivan and Crump 1984, $1986 a, b$, Sullivan et al. 1985a, $b, 1990 a, b$, Robinson 1990, Boag and Mlotkiewicz 1991, Merkens et al. 1991, Andelt et al. 1992, Vernet-Maury et al. 1992). Additional chemical and behavioral studies are needed to evaluate the repellency of constituents of predator scents in different target species and to determine the behavioral and environmental contexts in which such stimuli are most effective.

Sulfur-containing compounds are ubiquitous in urine, feces, and anal sac fluids of carnivores and are widely aversive to herbivores. Urine and feces from canids and felids contain a number of sulfur compounds, in many cases methylalkyl or methylaryl sulfides (red fox, Vulpes vulpes: Jorgenson et al. 1978, Wilson et al. 1978, Bailey et al. 1980, Vernet-Maury
1980; wolf, Canis lupus: Raymer et al. 1984; coyote: Murphy et al. 1978, Schultz et al. 1988; domestic dog, Canis familiaris: Schultz et al. 1985; bobcat, Felis rufus: Mattina et al. 1991; domestic cat, Felis cattus: Mattina et al. 1991; lion, Panthera leo: Abbott et al. 1990). Anal sac fluids from mustelids (Andersen and Bernstein 1980, Crump 1980a, b, Sokolov et al. 1980, Schildknecht et al. 1981, Brinck et al. 1983) and hyaenids (Wheeler et al. 1975, Buglass et al. 1990) also contain sulfur constituents, among them heterocycles such as thiolanes and thietanes.

Sulfur compounds from the anal sacs of mustelids inhibit browsing or cause area avoidance in the snowshoe hare, Lepus americanus (Sullivan and Crump 1984, Sullivan et al. 1985a), the European wild rabbit, Oryctolagus cuniculus (Robinson 1990), several species of Microtus (Sullivan et al. 1988a, 1990a, Merkens et al. 1991), the pocket gopher, Thomomys talpoides (Sullivan et al. 1988b, 1990b), the wood mouse, Apodemus sylvaticus, and the bank vole, Clethrionomys glareolus (Robinson 1990). Norway rats (Rattus norvegicus) and some of the species listed above avoid a number of sulfur compounds from feces of red fox and wolf (Vernet-Maury 1980, Sullivan and Crump 1986a, Sullivan et al. 1988a, Vernet-Maury et al. 1992). Red deer (Cervus elaphus), roe deer (Capreolus capreolus), black-tailed deer (Odocoileus hemionus columbianus), and domestic sheep reduce feeding in response to a sulfur-containing fraction of lion dung and other sulfurcontaining odorants (Abbott et al. 1990, Arnould and Signoret 1993, Lewinson et al. 1994).

The ubiquity of sulfur-containing chemicals in carnivore scents, and the overall repellency of carnivore scents to prey species suggest that sulfur odors are promising repellents. Accordingly, the present study was designed to evaluate the effects of sulfur-containing constituents of predator scents on feeding in the mountain beaver.

Mountain beavers exhibit avoidance responses to natural scents from a number of predators, but their responses to single constituents of predator scents have never been studied. Epple et al. (1993) and Nolte et al. $(1993,1994)$ found that anal sac fluid and urine from American mink and urine from bobcat, coyote, and domestic dog inhibit retrieval of food. Precipitation of sulfur-containing compounds with mercuric acetate reduces the repellency of coyote urine (Nolte et al. 1994). Taken together, these findings suggest that predator scents and some of their sulfur-containing constituents represent useful deterrents to foraging by mountain beavers.

\section{METHODS \\ Subjects}

Six adult male and six adult female mountain beavers, trapped in Washington State, served as subjects. The animals had been in the laboratory for several 
months prior to testing. They were familiar with the testing procedures but had never been exposed to the synthetic predator odors used in the present study. The animals were maintained on a reversed light cycle with red lamps providing dim light during the dark phase of the cycle. The number of hours of light and darkness reflected seasonal changes in the Pacific Northwest.

Subjects were housed individually in wire mesh cages, each consisting of two compartments $(66 \times 66 \times$ $183 \mathrm{~cm})$ connected by a door at floor level. A plastic nest box was provided in one of the compartments. Aspen chips covered the cage floor. Animals received a diet of Purina Guinea Pig Chow and Mazur Omnivore A pellets, supplemented with fresh greens, alfalfa, and apple. Water was available ad libitum.

\section{Test stimuli}

Coyote urine and the following synthetic predator scent constituents were used as test stimuli: $\Delta^{3}$-Isopentenyl methyl sulfide (IMS); 2,2-dimethylthietane (DMT); 2-propylthietane (PT); 3-propyl-1,2-dithiolane (PDT). IMS is the major volatile constituent of coyote urine (Schultz et al. 1988). It is also found in urine from wolf (Raymer et al. 1984), domestic dog (Schultz et al. 1985), and red fox (Jorgenson et al. 1978, Wilson et al. 1978, Bailey et al. 1980), and in mink anal sac fluid (Sokolov et al. 1980). DMT is the major volatile constituent of mink anal sac fluid (Sokolov et al. 1980, Schildknecht et al. 1981). PT and PDT are compounds from anal sac secretions from ferret and stoat (Crump $1980 a, b)$.

\section{Stimulus sources and preparation}

Urine from four adult male coyotes was collected at the Denver Wildlife Research Center Predator Facility in Millville, Utah. Donor animals were maintained on a diet consisting mainly of raw meat. Urine samples were pooled and frozen immediately after collection, shipped to the Monell Center on dry ice, and maintained frozen until used.

IMS was synthesized according to the procedure described by Wilson et al. (1978). A mass spectrum of the compound corresponded to the spectrum described by these authors. Homogeneity of the sample used for bioassays was confirmed by analytical high performance liquid chromatography (HPLC; Zorbax ODS 4.6 $\times 250 \mathrm{~mm}$ column; linear gradient of acetonitrile in water from 40 to $100 \%$ for $30 \mathrm{~min}$ at $1 \mathrm{~mL} / \mathrm{min}$; UV detection at $204 \mathrm{~nm}$ ).

DMT was synthesized according to the procedure described by Mayer (1974). The structure was confirmed by nuclear magnetic resonance (NMR) $\left[{ }^{1} \mathrm{H}\right.$ NMR (250 MHz, $\left.\mathrm{CDCl}_{3}\right) \delta 3.06(\mathrm{t}, \mathrm{J}=7.9 \mathrm{~Hz}, 2 \mathrm{H})$, $2.71(\mathrm{t}, \mathrm{J}=7.9 \mathrm{~Hz}, 2 \mathrm{H}), 1.58(\mathrm{~s}, 6 \mathrm{H}) ;{ }^{13} \mathrm{C} \mathrm{NMR}(62.5$ $\left.\mathrm{MHz}, \mathrm{CDCl}_{3} \delta 47.5,41.2,32.9,17.9\right]$.

Slow-release devices, containing a 1:1 mixture of PT and PDT, were donated by Phero-Tech Company (Delta, British Columbia, Canada). The compounds were incorporated at $1 \%$ by mass into polyvinyl chloride (PVC) rods, measuring $4 \times 0.04 \mathrm{~cm}$.

\section{Bioassay tests, experiments 1-4}

Caching of food from sources associated with predator odors was used as a measure of repellency and was interpreted as the result of risk assessment. The effects of scent stimuli on the retrieval of food were investigated in two-choice tests. Methods had been previously established using natural predator scents and had proven effective in assessing their repellent qualities (Epple et al. 1993). In each experiment listed below, subjects were presented with two stainless steel bowls, each containing 15 or $20 \mathrm{~g}$ of $2-\mathrm{cm}^{2}$ apple cubes and scented with a different odorant. Animals typically did not consume food at the food bowls but cached apple for subsequent consumption.

Choice tests were conducted in the subjects' home cages. For each test, bowls were placed $25 \mathrm{~cm}$ apart against the wall opposite the connecting door in the cage compartment that did not contain the nest. After 1 or $2 \mathrm{~h}$, the mass of apple left in each bowl was recorded. All subjects were tested twice with every set of stimuli in each experiment. The left-right position of scented bowls was counterbalanced across the two replications on each subject and across subjects. Each mountain beaver was tested only once daily, and not more than 3 times/wk. For all experiments, mean masses of food taken from experimental and control bowls were subjected to analysis of variance (ANOVA). The Kolmogorov-Smirnov test for normality was used to test the distribution of data in all experiments. Results were normally distributed across subjects.

\section{Experiment 1}

The aversiveness of coyote urine as a function of its concentration was evaluated in 2 -h tests. Whole urine and aqueous solutions containing 50, 25, 10, and $1 \%$ urine were tested. Fresh dilutions were prepared on each day of testing. Deionized water was used as a control stimulus. Prior studies had shown that urine from herbivores or novel odorants, such as butyric acid, have no effect on food retrieval by mountain beavers (Epple et al. 1993). Therefore, water was considered to be a valid control stimulus.

All subjects tested on the same day received urine of the same concentration. The order in which different urine concentrations were presented was randomized across subjects. Urine or water $(500 \mu \mathrm{L})$ was applied to filter paper disks ( $9 \mathrm{~cm}$ diameter). Disks were placed into the food bowls, and $20 \mathrm{~g}$ of apple was added to each bowl. Apple and stimulus disks were placed into separate areas of the large 1.9-L (2 quart) bowls in order to avoid contamination of food with urine.

\section{Experiment 2}

The repellency of IMS was investigated. Two concentrations of IMS, dissolved in light mineral oil, were 
tested: 10 and $1 \mathrm{mg} / \mathrm{mL}$. The concentration of $10 \mu \mathrm{g} /$ $\mathrm{mL}$ approximated the concentration of the compound in our pool of coyote urine as determined by HPLC analysis. Light mineral oil served as control in both series of trials.

Stimulus fluids $(500 \mu \mathrm{L})$ were presented in plastic mesh capsules (HistoPrep, Fisher Scientific, USA, 25 $\times 6 \mathrm{~mm}$ ) lined with filter paper. These scent dispensers were placed into each bowl, leaving the food untainted. They allowed animals to smell the stimuli but prevented contact with odorants. All subjects were tested with the lower concentration first, followed by the higher concentration. Choice tests offered $20 \mathrm{~g}$ of apple per bowl for $2 \mathrm{~h}$.

\section{Experiment 3}

The repellency of DMT was tested. Informal screening of DMT, using a few animals not included in the experiment, had suggested that the compound is not aversive. Therefore, in the present experiment whole coyote urine was tested on the same subjects in a counter-balanced design, in order to ascertain that possible failure to respond to DMT was not due to general habituation to predator scents.

DMT was prepared for testing by dissolving $100 \mu \mathrm{L}$ in $2 \mathrm{~g}$ of petroleum jelly. This preparation reduces feeding in European wild rabbits, woodmice, and voles (Robinson 1990). For each trial, $30 \mathrm{mg}$ of DMT jelly was placed into a paper-lined HistoPrep capsule. Petroleum jelly (30 mg) served as a control odorant. Paper-lined HistoPrep capsules also served as dispensers for $500 \mu \mathrm{L}$ of coyote urine and $500 \mu \mathrm{L}$ of water.

Half of all subjects tested on each day received choices between DMT and petroleum jelly; the other half received choices between coyote urine and water. Tests lasted for $1 \mathrm{~h}$, with $15 \mathrm{~g}$ of diced apple offered in each food bowl.

\section{Experiment 4}

The effect of commercial slow-release devices containing synthetic mustelid scent, i.e., a 1:1 mixture of PT and PDT, was tested. Blank plastic rods of the same dimensions as the devices served as controls. Scented devices and controls were enclosed in unlined HistoPrep capsules that were placed into bowls containing $20 \mathrm{~g}$ of diced apple. Tests lasted $2 \mathrm{~h}$.

\section{Bioassay tests, experiment 5}

The effects of long-term exposure to PT-PDT devices on food consumption was investigated using five subjects. In the course of this habituation experiment, each animal was exposed to PT and PDT continuously for $5 \mathrm{~d}$ while housed in a large room $(3.5 \times 3.5 \mathrm{~m})$. The room contained the subject's nest box, two metal tunnels (120 cm long, $15 \mathrm{~cm}$ diameter) to increase environmental complexity, a water bowl, and two feeding stations located $3 \mathrm{~m}$ from each other. One feeding station was scented using a PT-PD device enclosed in a
HistoPrep capsule, the other station contained a capsule with a blank device.

Feeding stations consisted of translucent plastic boxes $(40 \times 28 \mathrm{~cm}, \times 23 \mathrm{~cm}$ high $)$ with $13 \times 13 \mathrm{~cm}$ entrances. These boxes were used to concentrate volatiles emanating from the HistoPrep capsule taped to the back wall of each box. One of the two feeding stations, including the bowl, always was used to present predator scent, while the other always was used to present control scent.

Each subject was introduced into the room $24 \mathrm{~h}$ before predator scent was presented. During this period, $70 \mathrm{~g}$ of dry pellets were available in each feeding station, containing empty HistoPrep capsules. Dry chow was the only food available throughout the adaptation and test periods.

A 5-d test period followed adaptation. Each day at 1000 chow remaining in the feeding stations was removed and weighed, $70 \mathrm{~g}$ of fresh chow were placed in each feeding station, and HistoPrep capsules were supplied with fresh devices. The location of boxes in the room remained constant throughout the $5 \mathrm{~d}$ of testing, but positions of predator- and control-scented stations were determined daily at random. Methods used in Experiment 5 are identical to those employed in a previous study on habituation to coyote urine (Epple et al. 1993), with the exception that HistoPrep capsules rather than pieces of perforated tubing were used as scent dispensers.

\section{RESULTS \\ Experiment 1}

A three-factor ANOVA in which sex of subject was treated as an independent factor and differently scented stimulus bowls and concentrations were treated as dependent factors showed that there was a significant difference in retrieving of urine-scented as compared to water-scented food $(F=8.53, P<0.05)$ but no difference among stimulus concentrations. In addition, the interaction among the factors for stimulus type, concentration, and sex of subject was significant $(F=3.01$, $P<0.05)$. Otherwise, there were no significant differences (Fig. 1).

Post hoc $t$ tests showed that subjects, as a group, retrieved significantly more food from water-scented bowls than from bowls scented with $100 \%$ urine $(F=$ $12.23, P<0.005)$ or with $50 \%$ urine $(F=7.07, P<$ $0.05)$. Males, as a subgroup, exhibited a significant preference for water-scented food over food scented with $100 \%$ urine only $(F=23.78, P<0.01)$. Females, as a subgroup, took significantly more food from bowls scented with water than from bowls scented with $50 \%$ urine only $(F=7.43, P<0.05)$. However, females but not males showed a strong trend to prefer water-scented food in response to all urine concentrations (Fig. 1).

\section{Experiment 2}

A three-factor ANOVA in which sex of subject was treated as an independent factor and stimulus bowls 


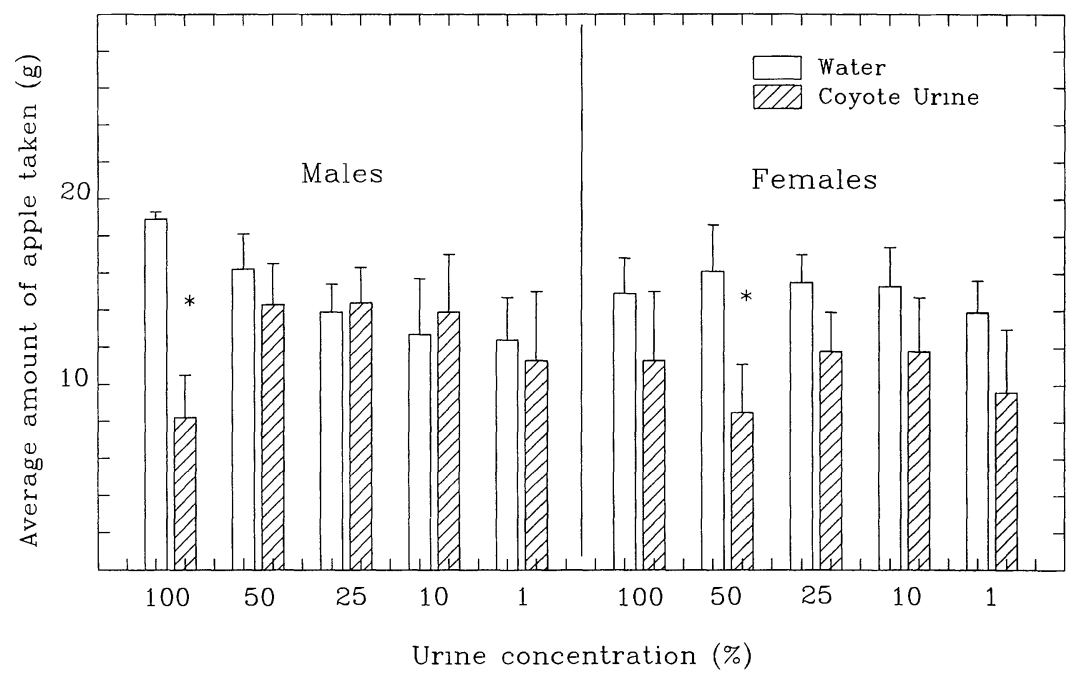

FIG. 1. Average amount of apple retrieved by male and female mountain beavers from bowls scented with different concentrations of coyote urine and from bowls scented with water; *significant difference. Data are means and 1 SE.

and IMS concentrations were treated as dependent factors failed to reveal any significant differences (Fig. 2). IMS did not affect food retrieval.

\section{Experiment 3}

A three-factor ANOVA in which sex of subject was treated as an independent factor and stimulus bowls and stimulus types as dependent factors showed that there were significant differences between males and females $(F=30.6, P<0.001)$, between stimulus bowls $(F=22.3, P<0.001)$, and an interaction between bowls and stimulus types $(F=9.44, P<0.05)$. The analysis was interpreted in terms of two-way interactions. Post hoc $t$ tests indicated that coyote urine significantly reduced food retrieval compared to water in male and female subjects $(F=8.66, P<0.05)$, but that DMT had no effect (Fig. 3). Females retrieved

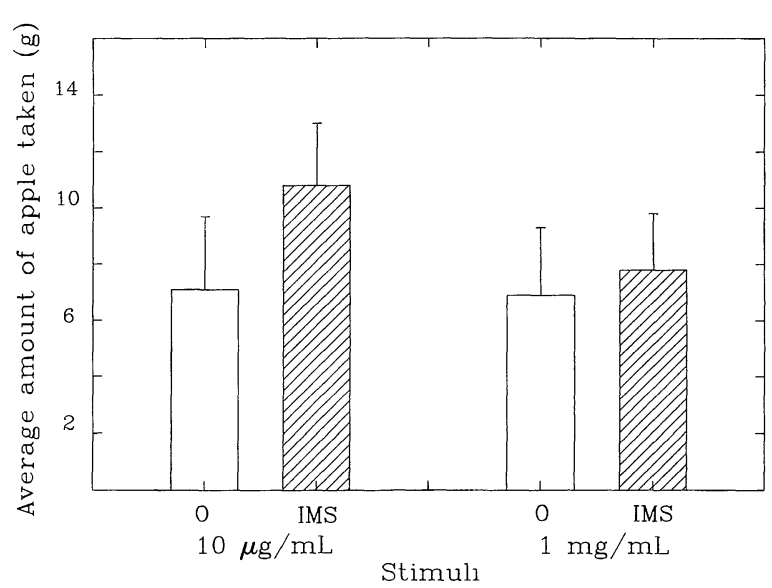

FIG. 2. Average amount of apple retrieved from bowls scented with two concentrations of IMS and from bowls scented with mineral oil $(\mathrm{O})$. Results from male and female mountain beavers are combined. Data are means and 1 SE. significantly less apple from coyote urine-scented bowls than did males $(F=14.5, P<0.005)$, but there were no sex differences in food caching in response to DMT.

\section{Experiment 4}

A two-factor ANOVA in which sex was treated as an independent factor and stimulus type as a dependent factor, showed that the animals, as a group, retrieved less apple from bowls scented with PT-PDT devices $(F=8.1, P<0.05)$. There was no significant difference between male and female subjects and no interaction between sex and stimulus type (Fig. 4).

\section{Experiment 5}

A three-factor ANOVA, in which sex was treated as an independent factor, and days of exposure and stim-

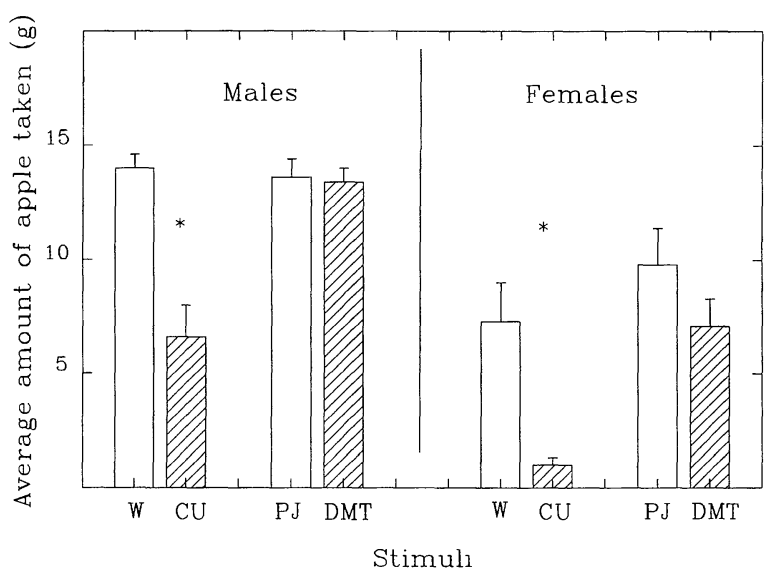

FIG. 3. Average amount of apple retrieved by male and female mountain beavers when offered choices between coyote urine (CU) and water (W) scented food, or between DMT and petroleum jelly (PJ) scented food; *significant difference. Data are means and $1 \mathrm{SE}$. 


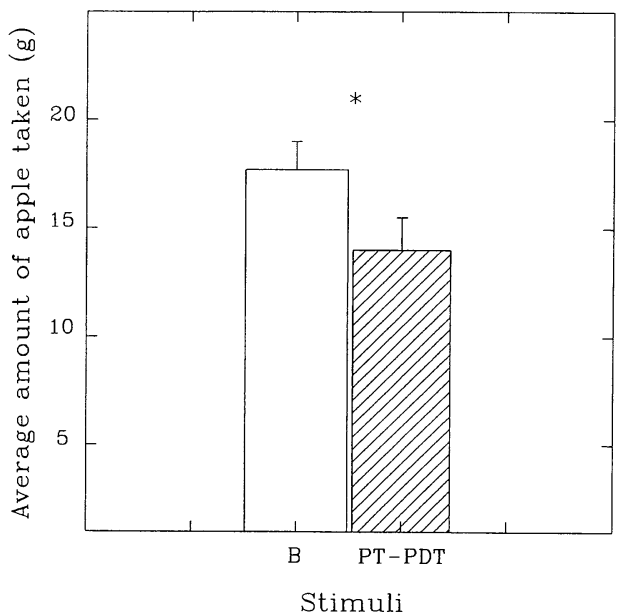

FIG. 4. Average amount of apple retrieved from bowls scented with PT-PDT devices and from bowls scented with blank devices (B). Results from male and female mountain beavers are combined, *significant difference. Data are means and $1 \mathrm{SE}$.

ulus bowls were treated as dependent factors, failed to reveal significant differences (Fig. 5). This indicates that the PT-PDT devices did not influence feeding when subjects were continuously exposed to them.

\section{DISCUSSION}

The present results are consistent with our previous finding (Epple et al. 1993, Nolte et al. 1993, 1994) that coyote urine is an effective feeding deterrent for the mountain beaver. However, feeding from urine-scented sources is not completely suppressed, and there is individual variability in response to this stimulus. The interaction among sex of subject, stimulus type, and stimulus dilution found in Experiment 1 and the significant sex difference in response to whole coyote urine in Experiment 3 suggest that males are less sensitive than females to aversive urinary cues. Mountain beaver males are considerably heavier than females (Nowak 1991). Their absolute energy requirements are probably higher than those of females, and this may cause them to take a higher predation risk during foraging.

The sulfide from canid urine (IMS) and the major sulfur constituent of mink anal sac fluid (DMT) had no effect on food retrieval. PT and PDT reduced food retrieval for short periods of time. Subjects habituated quickly to these odors, however. This is in strong contrast to the mountain beavers' responses to coyote urine. When five animals were tested with whole coyote urine under conditions identical to those used in Experiment 5 , no habituation occurred during the entire 5-d test period (Epple et al. 1993). In another study, plants sprayed with coyote urine were avoided for up to $3 \mathrm{wk}$ (Nolte et al. 1993).

IMS and DMT are not aversive to mountain beavers, in spite of the fact that they are major volatile constituents of natural predator scents that are effective repellents for this species. This indifference is surprising, in light of the widespread repellency of sulfurcontaining compounds and our previous finding that precipitation of such compounds in coyote urine reduces its repellent qualities for mountain beavers (Nolte et al. 1994). Moreover, several other species respond to DMT and IMS. DMT is a strong feeding deterrent for snowshoe hares (Sullivan and Crump 1984) and European wild rabbits and reduces trap entry in wood mice and bank voles (Robinson 1990). IMS also reduces browsing in snowshoe hares (Sullivan and Crump 1986a). PT and PDT, to which mountain beavers habituate quickly, are strong, long-lasting repellents for a number of small mammals (Sullivan and Crump 1984, Sullivan et al. 1988a, $b, 1990 a, b$, Merkens et al. 1991).

Mountain beavers respond to the same natural predator scents that repel other herbivores but are largely indifferent to some of the constituents to which other

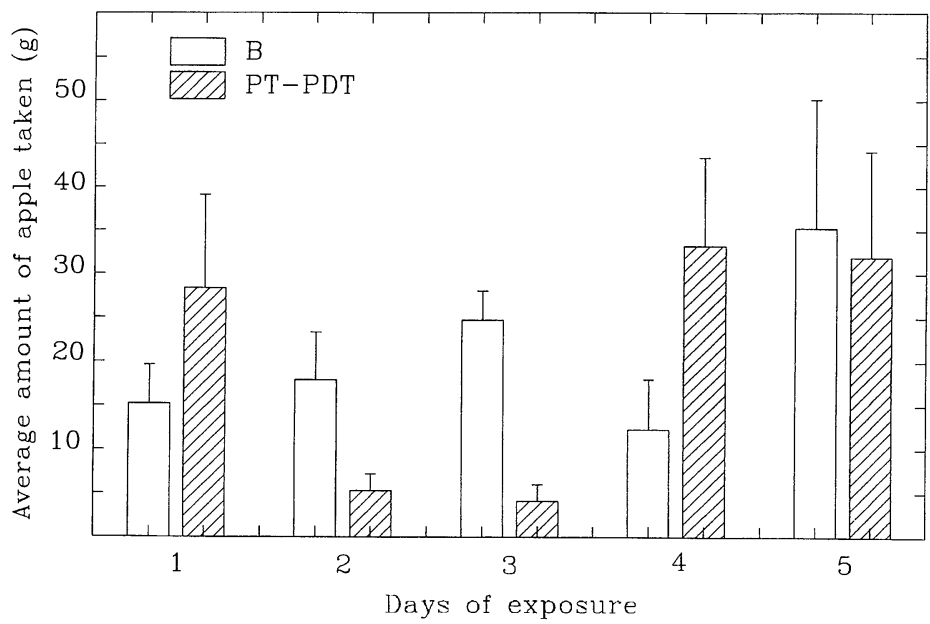

Fig. 5. Average amount of dry chow taken from feeding stations scented with PTPDT devices and from feeding stations scented with blank devices (B) during $5 \mathrm{~d}$ of exposure to the devices. Results from male and female mountain beavers are combined. Data are means and 1 SE. 
species respond strongly. This could be interpreted in several ways. The aversiveness of natural predator scents for mountain beavers may depend on one or a few key compounds other than those tested here. Conversely, mountain beavers may respond to a mixture of compounds present in natural predator scents. Although the synthetic compounds tested in the present study may be active components of such scent mixtures, they may not have a measurable repellency by themselves. Some other herbivores also respond more strongly to complex natural scents than to single compounds or simple mixtures (Vernet-Maury et al. 1984, Sullivan and Crump 1986a, Abbott et al. 1990).

Although many herbivores are repelled by selected key compounds in predator scents, these compounds may not be identical for each species that responds to the natural scent mix. Moreover, additional constituents of the mixture may enhance the effectiveness of key compounds in a species-specific manner. Thus, predator-derived compounds have high potential as feeding repellents for a number of herbivores, including mountain beavers. However, the constituents of natural predator scents to which this species is most responsive must be isolated and identified before effective repellents can be formulated.

\section{ACKNOWLEDGMENTS}

The studies were supported through Cooperative Agreement Number 12-34-41-CC40 [CA] between the Denver Wildlife Research Center and the Monell Chemical Senses Center. We thank the Phero-Tech Company for donating the PT-PDT devices and John McConnell of the DWRC Facility in Millville for collecting coyote urine.

\section{Literature Cited}

Abbott, D. H., D. A. Baines, C. G. Faulkes, D. C. Jennens, P. C. Y. K. Ning, and A. J. Tomlinson. 1990. A natural deer repellent: chemistry, and behavior. Pages 599-609 in D. W. Macdonald, D. Müller-Schwarze, and S. E. Natynczuk, editors. Chemical signals in vertebrates V. Oxford University Press, Oxford, UK.

Albone, E. S. 1984. Mammalian semiochemistry. John Wiley and Sons, New York, New York, USA.

Andelt, W. F., D. L. Baker, and K. P. Burnham. 1992. Relative preference of captive cow elk for repellent treated diets. Journal of Wildlife Management 56:164-173.

Andersen, K. K., and D. T. Bernstein. 1980. Sulfur compounds in mustelids. Pages 399-406 in D. Cavallini, G. E. Gauli, and V. Zappia, editors. Natural sulfur compounds. Plenum, New York, New York, USA.

Arnould, C., and J. P. Signoret. 1993. Sheep food repellents: efficacy of various products, habituation, and social facilitation. Journal of Chemical Ecology 19:225-236.

Bailey, S., P. J. Bunyan, and J. M. J. Page. 1980. Variation in the levels of some components of the volatile fraction of urine from captive red foxes and its relationship to the state of the animal. Pages 391-403 in D. Müller-Schwarze and R. M. Silverstein, editors. Chemical signals in vertebrates and aquatic invertebrates. Plenum, New York, New York, USA.

Boag, B., and J. A. Mlotkiewicz. 1991. Evaluation of an odour derived from lion faeces on the behavior of wild rabbits. Tests of Agrochemicals and Cultivars 12:18-19.

Brinck, C., S. Erlinge, and M. Sandell. 1983. Anal sac se- cretions in mustelids: a comparison. Journal of Chemical Ecology 9:727-745.

Buglass, A. J., F. M. C. Darling, and J. S. Waterhouse. 1990. Analysis of the anal sac secretion of the Hyaenidae. Pages 65-69 in D. W. Macdonald, D. Müller-Schwarze, and S. E. Natynczuk, editors. Chemical signals in vertebrates V. Oxford University Press, Oxford, UK.

Campbell, D. L. 1994. Mountain beaver. Pages B53-B60 in S. E. Hyngstrom and R. M. Timm, editors. Prevention and control of wildlife damage. Volume 2. University of Nebraska Cooperative Extension Service, in cooperation with United States Department of Agriculture, Animal and Plant Health Inspection Service, Animal Damage Control, and Great Plains Agricultural Council, Lincoln, Nebraska, USA.

Crump, D. R. $1980 a$. Anal gland secretion of the ferret (Mustela putorius forma furo). Journal of Chemical Ecology 6 : 837-844.

1980b. Thietanes and dithiolanes from the anal gland of the stoat (Mustela erminea). Journal of Chemical Ecology 6:341-347.

Epple, G., J. R. Mason, D. L. Nolte, and D. L. Campbell. 1993. Effects of predator odors on feeding in the mountain beaver (Aplodontia rufa). Journal of Mammalogy 74:715722.

Feldhamer, G. A., and J. A. Rochelle. 1982. Mountain beaver-Aplodontia rufa. Pages 167-175 in J. A. Chapman and G. A. Feldhamer, editors. Wild mammals of North America. Johns Hopkins University Press'; Baltimore, Maryland, USA.

Gorman, M. L. 1984. The responses of prey to stoat (Mustela erminea) scent. Journal of Zoology (London) 202:419-423.

Jorgenson, J. W., M. Novotny, M. Carmack, G. B. Copland, S. R. Wilson, S. Katona, and W. K. Whitten. 1978. Chemical scent constituents in the urine of the red fox (Vulpes vulpes L.) during the winter season. Science 199:796-798.

Lewinson, R., J. N. Bean, E. V. Aronov, and J. R. Mason. 1994. Similarities between Big Game Repellent and predator urine repellency to white-tailed deer: the importance of sulfur and fatty acids. Eastern Wildlife Damage Management Conference 6, in press.

Lima, S. L., and L. M. Dill. 1990. Behavioral decisions made under the risk of predation: a review and prospectus. Canadian Journal of Zoology 68: 619-640.

Macdonald, D. W. 1985. The carnivores: Order Carnivora. Pages 619-722 in R. E. Brown and D. W. Macdonald, editors. Social odours in mammals. Volume 2. Clarendon, Oxford, UK.

Mason, J. R., G. Epple, and D. L. Nolte. 1994. Semiochemicals and improvements in rodent control. Pages 327-346 in B. E. Galef, M. Mainardi, and P. Valsecchi, editors. Behavioral aspects of feeding: basic and applied research in mammals. Harwood Academic, Chur, Switzerland.

Mattina, M. J. I., J. J. Pignatello, and R. K. Swihart. 1991. Identification of volatile components of bobcat (Lynx rufus) urine. Journal of Chemical Ecology 17:451-462.

Mayer, A. 1974. Eine einfache Synthese von 2,2,-Dimethylthietan. Helvetia Chimica Acta 57:2514.

Merkens, M., A. S. Harestad, and T. Sullivan. 1991. Cover and efficacy of predator-based repellents for Townsend's vole, Microtus townsendii. Journal of Chemical Ecology 17:401-412.

Müller-Schwarze, D. 1972. Responses of young black-tailed deer to predator odors. Journal of Mammalogy 53:393-394.

Murphy, E. L., R. A. Flath, D. R. Black, T. R. Mon, R. Teranishi, R. M. Tim, and W. E. Howard. 1978. Isolation, identification and biological activity assay of chemical fractions from estrus urine attractive to the coyote. Pages 6677 in R. W. Bullard, editor. Flavor chemistry of animal foods, American Chemical Society Symposium Series 
Number 67. American Chemical Society, Washington, D.C., USA.

Nolte, D. L., J. P. Farley, D. L. Campbell, J. R. Mason, and G. Epple. 1993. Potential repellents to prevent mountain beaver damage. Crop Protection 12:624-626.

Nolte, D. L., J. R. Mason, G. Epple, E. Aronov, and D. L. Campbell. 1994. Why are predator urines aversive to prey? Journal of Chemical Ecology 20:1505-1516.

Nowak, R. M. 1991. Walker's mammals of the world. Fifth edition. Johns Hopkins University Press, Baltimore, Maryland, USA.

Raymer, J., D. Wiesler, M. Novotny, C. Asa, U. S. Seal, and L. D. Mech. 1984. Chemical scent constituents in urine of wolf and their dependence on reproductive hormones. Journal of Chemical Ecology 12:297-314.

Robinson, I. 1990. The effect of mink odor on rabbits and small mammals. Pages 567-572 in D. W. Macdonald, D Müller-Schwarze, and S. E. Natynczuk, editors. Chemical signals in vertebrates V. Oxford University Press, Oxford, UK.

Schildknecht, H., C. Birkner, and D. Krauss. 1981. Struktur und Wirkung der Musteliden-Ökonome II. Erweiterte Analyse des Analbeutelsekretes des Nerzes Mustela vison L. Chemiker Zeitung 105:273-286.

Schultz, T. H., S. M. Kruse, and R. A. Flath. 1985. Some volatile constituents of female dog urine. Journal of Chemical Ecology 11:169-175.

Schultz, T. H., R. A. Flath, D. J. Stern, T. R. Mon, R. Teranishi, S. McKenna Kruse, B. Butler, and W. E. Howard 1988. Coyote estrous urine volatiles. Journal of Chemica Ecology 14:701-712.

Sokolov, V. E., V. E. Albone, P. F. Flood, P. F. Heap, M. Z. Kagan, V. S. Vasilieva, V. V. Roznov, and E. P. Zinkevich. 1980. Secretion and secretory tissues of the anal sac of the mink, Mustela vison. Journal of Chemical Ecology 6:805825.

Sullivan, T. P., and D. R. Crump. 1984. Influence of mustelid scent gland compounds on the suppression of feeding by snowshoe hares (Lepus americanus). Journal of Chemical Ecology 10:1809-1821.

Sullivan, T. P., and D. R. Crump. 1986a. Feeding responses of snowshoe hares (Lepus americanus) to volatile constituents of red fox (Vulpes vulpes) urine. Journal of Chemical Ecology 12:229-239.

Sullivan, T. P., and D. R. Crump. 1986b. Avoidance response of pocket gophers (Thomomys talpoides) to mustelid anal gland compounds. Pages 519-531 in D. Duvall, D. MüllerSchwarze, and R. M. Silverstein, editors. Chemical signals in vertebrates IV, ecology, evolution, and comparative biology. Plenum, New York, New York, USA.
Sullivan, T. P., D. R. Crump, and D. S. Sullivan. 1988a. Use of predator odors as repellents to reduce feeding damage by herbivores. III. Montane and meadow voles (Microtus montanus and Microtus pennsylvanicus). Journal of Chemical Ecology 14:363-377.

Sullivan, T. P., D. R. Crump, and D. S. Sullivan. 1988b. Use of predator odors as repellents to reduce feeding damage by herbivores. IV. Northern pocket gophers (Thomomys talpoides). Journal of Chemical Ecology 14:379-389.

Sullivan, T. P., D. R. Crump, H. Wieser, and A. Dixon. $1990 a$ Comparison of release devices for stoat (Mustela erminea) semiochemicals used as montane vole (Microtus montanus) repellents. Journal of Chemical Ecology 16:951-957.

Sullivan, T. P., D. R. Crump, H. Wieser, and A. Dixon. $1990 \mathrm{~b}$. Responses of pocket gophers (Thomomys talpoides) to an operational application of synthetic semiochemicals of stoat (Mustela erminea). Journal of Chemical Ecology 16: 941-949.

Sullivan, T. P., L. O. Nordstrom, and D. S. Sullivan. $1985 a$. Use of predator odors as repellents to reduce feeding damage by herbivores. I. Snowshoe hares (Lepus americanus). Journal of Chemical Ecology 11:903-909.

Sullivan, T. P., L. O. Nordstrom, and D. S. Sullivan. $1985 b$. Use of predator odors as repellents to reduce feeding damage by herbivores. II. Black-tailed deer (Odocoileus hemionus columbianus). Journal of Chemical Ecology 11:921935

Swihart, R. K. 1991. Modifying scent marking behavior to reduce woodchuck damage to fruit trees. Ecólogical Applications 1:98-103.

Vernet-Maury, E. 1980. Trimethyl-thiazoline in fox feces: a natural alarming substance for the rat. Page 407 in $\mathrm{H}$. van der Starre, editor. Olfaction and taste VII. Information Retrieval, Washington, D.C., USA.

Vernet-Maury, E., B. Constant, and J. Chanel. 1992. Repellent effect of trimethyl-thiazoline in the wild rat Rattus norvegicus Berkenhout. Pages 305-310 in R. L. Doty and D. Müller-Schwarze, editors. Chemical signals in vertebrates VI. Plenum, New York, New York, USA.

Vernet-Maury, E., E. H. Polak, and A. Demael. 1984. Structure/activity relationship of stress inducing odorants in the rat. Journal of Chemical Ecology 10:1007-1018.

Wheeler, J. W., D. W. Von Endt, and C. Wammer. 1975. Thiomethyl-pentane-2,3-dione. A unique natural compound from the striped hyaena. Journal of the American Chemical Society 97:441.

Wilson, S. R., M. Carmack, M. Novotny, J. W. Jorgenson, and W. K. Whitten. 1978. $\Delta^{3}$-Isopentenyl methyl sulfide. A new terpenoid in the scent mark of the red fox. Journal of Organic Chemistry 43:4675-4676. 